\title{
Bilateral muscular axillary arch: An anatomic study and clinical considerations
}

\author{
Chunder $\mathbf{R}^{1}$, Guha $\mathbf{R}^{2}$ \\ ${ }^{1}$ Associate Professor, Dept. of Anatomy, K.P.C. Medical College \& Hospital, 1F, Raja S.C. Mullick Road, \\ Jadavpur, Kolkata-700032
}

${ }^{2}$ Professor \& HOD, Dept. of Anatomy, CMS-TH, Bharatpur, Chitwan, Nepal

\section{ABSTRACT}

The axillary arch is a variative muscular slip encountered in the axillary region which usually connects latissimus dorsi to pectoralis major. Reported here is a rare case of bilateral axillary arch splitting the radial nerve into two roots in each side as observed during routine dissection of the axillary region of an old male cadaver. The anatomy, surgical implications, and embryology of the anomalous muscle have been discussed. Clinicians should be aware of its existence as it can give rise to different pathologies. It should be recognised and excised to expose the axillary artery and vein in patients with trauma and to perform axillary lymphadenectomy or axillary bypass. It should be considered in the differential diagnosis of axillary masses or in a history of intermittent axillary vein obstruction.

KEYWORDS: Axillary arch, latissimus dorsi, radial nerve.

\section{INTRODUCTION}

Anatomical variations of the axilla are of great relevance due to increasing surgical importance of the region for breast cancer surgery, reconstruction procedures and axillary bypass operations. Axillary arch, differently known as "axillopectoral arch", "Achselbogen muscle", "Langer's muscle", "Langer's axillary arch", "pectodorsal muscle", "axillopectoral muscle" or "arcus axillaris" is one such variation. It is described as a muscular slip, varying from 7 to $10 \mathrm{~cm}$ in length and 5 to $15 \mathrm{~mm}$ in breadth. ${ }^{1-3}$ It may be of different dimensions and variable presentation. It may extend from latissimus

Correspondence: Dr. Ranjit Guha

E-mail: guharanjit@yahoo.co.in dorsi in the posterior fold of the axilla, to the pectoralis major in the anterior fold, to the short head of the biceps brachii or to the coracoid process creating a close relationship with the elements of the axillary neurovascular bundle. Many variants of this anomaly have been observed. It was first identified by Alexander Ramsay in 1795, though described by him in 1812 as a muscular bundle connecting pectoral muscle and latissimus dorsi. However, the muscle has been named after Langer who gave the first description of the muscle in $1846 .{ }^{1}$ Most of the anatomists supposed the muscular arches in the axillary region to be rudimentary remnants of the "panniculus carnosus", a phylogenetically well-developed muscular structure 
found in lower mammalians where it gains attachment to the skin of the limbs so that the animals can shake their skin. ${ }^{4,5}$

\section{CASE REPORT}

During routine dissection of both axillae of an old male cadaver, presence of the axillary arch muscle was noted on either side. It took origin from latissimus dorsi and teres major (Fig. 2) and passed upwards and medially splitting the radial nerve into two roots. The muscle passed posterior to the bulk of axillary vascular bundle (Fig.1). It then split into four slips: the medial most slip merged with the serratus anterior muscle, another with the pectoralis major muscle, middle slip gained attachment to the root of the coracoid process along with common tendon of origin of the short head of biceps brachii and coracobrachialis, while the main bulk of muscle merged with the capsule of shoulder joint along with the attachment of subscapularis (Fig. 3). The dimension of the muscle in the right side was 6.1 $\mathrm{cm}$ by $1.2 \mathrm{~cm}$, while on the left $5.9 \mathrm{~cm}$ by $1.2 \mathrm{~cm}$. The position of the axillary arch, its bilateral presence, splitting of the radial nerve, and multiple connective tissue attachments of the arch made the case most unique.

\section{Figure : I}

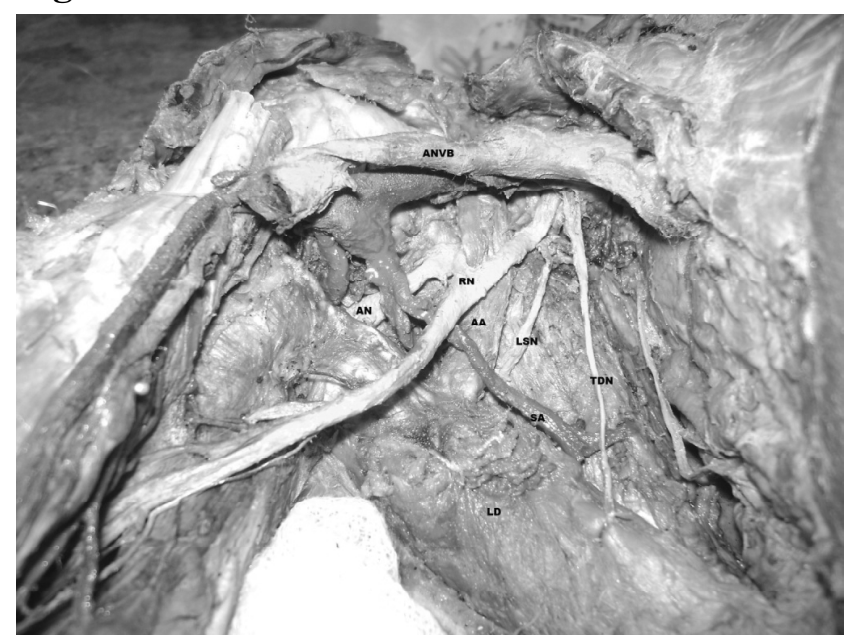

\section{FIGURE 1:}

Right axilla showing the axillary arch (AA) splitting the radial nerve $(\mathrm{RN})$ into two roots and passing posterior to the bulk of the axillary neurovascular bundle (ANVB).

AN: Axillary nerve, LSN: Lower subscapular nerve, SA: Subscapular artery, LD: Latissimus dorsi, TDN: Thoracodorsal nerve.

\section{Figure : II}

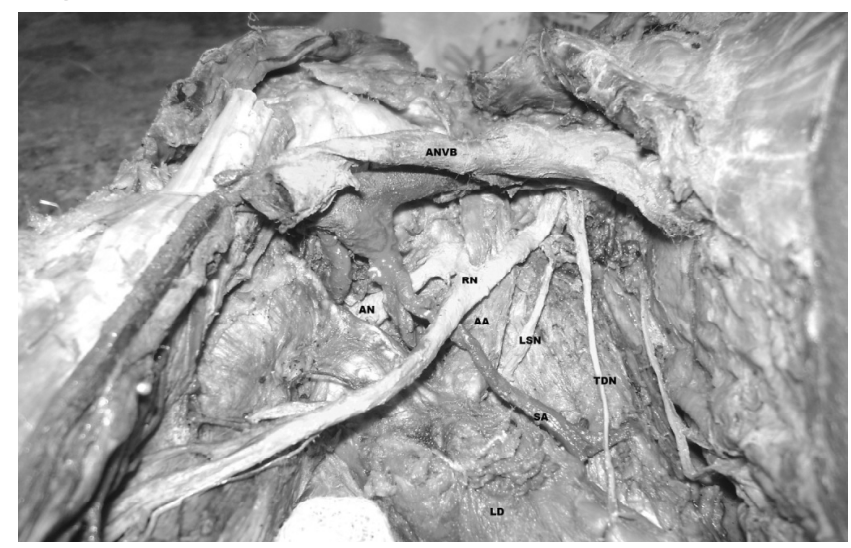

FIGURE 2:

Left axilla showing the axillary arch (AA) splitting the radial nerve $(\mathrm{RN})$ into two roots and extending from the Latissimus dorsi (LD) and Teres major (TM).

ANVB: Axillary neurovascular bundle, AN: Axillary nerve, USN: Upper subscapular nerve, SA: Subscapular artery, LD: Latissimus dorsi, TDN: Thoracodorsal nerve.

\section{Figure : III}

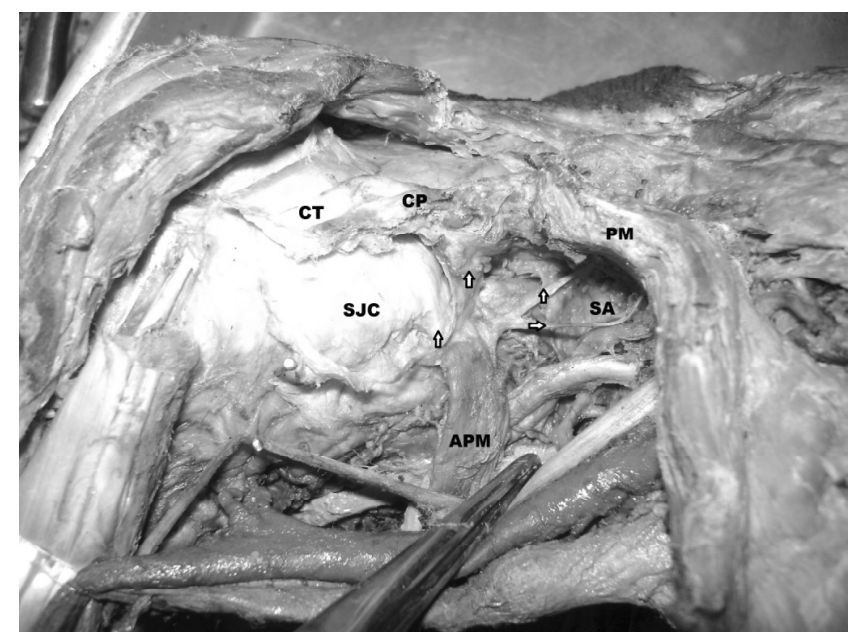




\section{FIGURE 3:}

Right axilla showing the multiple attachments of the axillary $\operatorname{arch}(\mathrm{AA})$ muscle (indicated by arrows). The medial most slip attached to serratus anterior (SA), another to the pectoralis major (PM), middle slip into the root of the coracoid process (CP) along with common tendon of origin of the short head of biceps brachii and coracobrachialis (CT), while the main bulk of muscle merged with the capsule of shoulder (SJC) along with the attachment of subscapularis

\section{DISCUSSION}

In the past, the axillary arch has been defined as a muscular arch which crosses from the edge of latissimus dorsi, midway in the posterior axillary fold, over the front of the axillary vessels and nerves to join the tendons of pectoralis major, coracobrachialis or the fascia over the biceps. ${ }^{6}$ The frequency is $0.25 \%$ to $43.8 \%$ depending on the population studied and the prevalence is $7-27 \% .{ }^{4} \mathrm{~A}$ possible genetic basis was found in patient of trisomy $13 .^{7}$ The prevalence was more among Chinese than in Caucasians and more common in females than in males. ${ }^{1}$ It is usually bilateral but can occur unilaterally. ${ }^{8}$

Testut classified these muscular bands as complete and incomplete. ${ }^{9}$ The complete form reached the tendon of the pectoralis major near its site of insertion on the humerus; in the incomplete form, the axillary arch extended from the latissimus dorsi to the axillary fascia, biceps brachii muscle, coracobrachialis muscle, the distal end of the bicipital groove, the inferior edge of the pectoralis minor muscle or the coracoid process. ${ }^{10}$ In the present case, the muscular slip on either side was of incomplete form. It passed deep to the axillary vessels but was enclosed by two roots of the radial nerve which united at the lower border of the muscle. There was no mention in any of these cases of additional attachments to surrounding structures. The case reported here is unique in that the muscular slip was attached to multiple structures such as bone (coracoid process and shoulder joint capsule), tendon (common tendinous origin of biceps brachii and coracobrachialis) and muscles (pectoralis major and serratus anterior). Wilson studied the nerve supply of this muscular arch and described four sources of its innervation: branch from anterior thoracic nerve (commonest), nerve of Wrisberg (from internal anterior thoracic nerve), branch from intercosto-brachial nerve and branch from lateral ramus of first intercostals nerve. ${ }^{11}$

Limb muscles arise from the somatic layer of the lateral plate mesoderm surrounding the developing bones. ${ }^{12}$ Cihak described four fundamental phases in the ontogenesis of muscle pattern. ${ }^{13}$ The muscle anomaly described here could have arisen during phases 3 and 4 of ontogenesis of the muscles in the axilla. During phase 3 , some muscle primordial from different layers fuse to form a single muscle. Grim however, stated that some muscle primordial undergo cell death, despite the cell differentiation to the point of containing myofilaments. ${ }^{14}$ Persistence of some cells between latissimus dorsi and teres major may account for the muscular slip in the case described. During phase 4, there is integration between the connective tissue elements and the muscle fibres; the multiple connective tissue attachments in the present case probably formed during this stage.

Axillary muscular arch is considered to be rudimentary remnants of the "panniculus carnosus", which is an embryological remnant of a more extensive sheet of skin associated musculature, lying at the junction 
between the superficial fascia and subcutaneous fat. This structure is well developed in lower mammals, particularly rodents, while in higher primates and humans it is evident only as muscle such as platysma and dartos; in the remainder of body it becomes vestigial. ${ }^{15}$ In lower mammals, the panniculus carnosus is highly developed to form the pectoral group of muscles. However, in man, it has regressed because its functional importance decreased during evolution in favour of wider upper limb mobility. ${ }^{16}$ In humans, Langer's arch is therefore the most common embryologic remnant of the panniculus carnosus in the pectoralis group of muscles. ${ }^{4}$

Axillary arch was reported to cause compression of the neurovascular bundle and restrict particularly the abduction and lateral rotation of the shoulder joint. ${ }^{1}$ It can occasionally be palpable during routine clinical examinations when, presenting as an axillary mass, it can be confused with enlarged lymph nodes or soft tissues tumours. Clinical features such as intermittent axillary vein obstruction or a finding of fullness within the axilla itself can be clinically useful but MRI scan may be required to confirm the diagnosis. ${ }^{17}$ Clinically it has been implicated in costoclavicular compression syndrome, axillary vein entrapment, median nerve entrapment, hyperabduction syndrome, thoracic outlet syndrome and shoulder instability syndrome. ${ }^{18,19}$ Furthermore, it may cause hindrance during axillary lymphadenectomy or lymph node biopsy causing difficulty in reaching the lymph nodes lying deeply. In such cases, surgeons are obliged to cut the arch to avoid both the omission of the lymph nodes posterior to it and the local recurrence of the disease. Identification of Langer's arch or its remnant may be of particular importance when performing sentinel node biopsy, because for the need of adequate exposure and good haemostasis during this procedure. ${ }^{20,21}$
Access for bypass surgery using the axillary vessels may be compromised if there is failure to identify Langer's arch. ${ }^{22}$ Ischaemic necrosis has complicated latissimus dorsi breast reconstruction if the thoracodorsal pedicle is stretched or compressed by an unsuspected axillary arch. ${ }^{23}$

\section{CONCLUSION}

It is important that surgeons operating in the axilla and physicians treating vague unexplained neurovascular symptoms of upper limb be aware of this not uncommon anatomic variant. The entrapment of the muscle by the two roots of the radial nerve may produce neurological symptoms during movement of the arm. When present, Langer's arch should always be accurately identified and formally divided to allow adequate exposure of axillary contents to achieve a complete lymphatic dissection and preserve vascular, lymphatic and nervous structures.

\section{REFERENCES}

1. Besana-Ciani I, Greenall MJ. Langer's axillary arch: anatomy, embryological features and surgical implications. Surgeon 2005; 3:325-7.

2. Kasai T, Chiba S. True nature of the muscular arch of axilla and its nerve supply. Kaibogaku Zasshi 1977; 25:657-69.

3. Kanaka S, Pulipati AK, Gaikwad MR. Axillary arch and its relations - a rare case report. Int J Biol Med Res 2012;3 (3):2277-9.

4. Bonastre V, Rodriguez-Niedenfuhr M, Choi D, et al. Coexistence of a pectoralis quartus muscle and an 
unusual axillary arch: case report and review. Clin Anat 2002;15:366-70.

5. Hollinshead WH. Pectoral region, Axilla, Shoulder and Arm. In: Hollinshead WH, editor. Text Book of Anatomy. $2^{\text {nd }}$ edi. New York: Harper \& Row; 1967. p.184.

6. Jhonson D, Ellis H. Pectoral girdle, shoulder region and axilla. In: Standring S, editor. Gray's Anatomy. $39^{\text {th }}$ ed. Philadelphia, USA: Elsevier Churchill Livingstone; 2005. p.837.

7. Aziz MA. Anatomical defects in a case of trisomy 13 with a D/D translocation. Teratology. 1980; 22:217-27.

8. Merida-Velasco JR, Rodriguez Vazquez JF, Merida Velasco JA, Sobrado Perez J, Collado JJ. Axillary arch: potential cause of neurovascular compression syndrome. Clin Anat. 2003;16:514-9.

9. Testut L. Les Anomalies Muscularies chez l'Homme Expliques par l'Anatomie Comparee. Paris: Masson; 1892.p.370-406.

10. Bryce TH. Myology. In: Schaefer EA, Symington J, Bryce TH, editors. Quain's elements of anatomy. $11^{\text {th }}$ ed. Vol IV, part II. London: Longmans Green \& Co; 1923. p.101-3.

11. Wilson JT. The innervation of the Achselbogen muscle. J Anat Physiol 1912; 47(1):8-17.

12. Carlson BM, Patten BM . Patten's Foundations of Embryology. $4^{\text {th }}$ ed. New York: McGraw-Hill; 1981. p.30810.

13. Cihak R. Ontogenesis of the skeleton and intrinsic muscles of the human hand and foot. Advances in Anatomy Embryology and Cell Biology 1972; 46:1-194.

14. Grim M. Development of the primordia of the latissimus dorsi muscle of the chicken. Folia Morphol (Praha) 1972; $19(3): 252-8$.
15. Salmons S. Muscle. In: Gray's Anatomy. Williams PL, Bannister LH, Berry MM, Collins P, Dyson M, Dussek JE et al (editors). $38^{\text {th }}$ edition. Churchill Livingstone: New York, 1995. p. 782-3.

16. Bergman RA, Afifi AK, Ryosuke M. Panniculus Carnosus. Opus IÂ: Muscolar System. In: Illustrated Encyclopedia of Human Anatomic Variation [book on the internet]. US: University of Iowa [cited 2009may]. Available form: http://www.janela1.com/vh/docs/ v0000978.htm.

17. Suzuma T, Sakurai T, Yoshimura G, Umemura T, Shimizu Y, Yang QF et al. Magnetic resonance axillography for preoperative diagnosis of the axillopectoral muscle (Langer's axillary arch): a case report. Breast Cancer 2003; 10(3):281-3.

18. Merida-Velasco JR, Rodriguez Vasquez JF, MeridaVelasco JA, Sobrado Perez J, Collado JJ. Axillary arch: potential cause of neurovascular compression syndrome. Clin Anat 2003; 16:514-9.

19. Clarys JP, Barbaix E, Van Rompaey H, Caboor D. The muscular arch of the axilla revisited: itspossible role in the thoracic outlet and shoulder instability syndromes. Man Ther 1996;1(3):133-9.

20. Sharma T, Singla RK, Agnihotri G, Gupta R. Axilary arch muscle. KUMJ 2009; 7(4): 432-4.

21. Petrasek AJ, Semple JL, McCready DR. The surgical and oncologic significance of the axillary arch during axillary lymphadenectomy. Can J Surg 1997; 40:44-7.

22. Serpell JW, Baum M. Significance of Langer's axillary arch in axillary dissection. Aust N Z J Surg 1991; 61:310-2.

23. Miguel M, Llusa M, Ortiz JC, Porta N, Lorente M. The axillopectoral muscle (of Langer): report of three cases. Surg Radiol Anat 2001; 23(5):341-3. 